\title{
ARTIFICIAL INTELLIGENCE MACHINING PREDICTIONS BY FUZZY GUI FOR INCONEL 718 WITH PVD COATED CARBIDE CUTTING TOOL
}

\author{
PRAVIN P. PANDE ${ }^{1} \&$ RAJESHKUMAR U. SAMBHE ${ }^{2}$ \\ ${ }^{1}$ Assistant Professor Department of Mechanical Engineering, Rajrshi Shahu College of \\ Engineeering Buldana, Maharashtra, India \\ ${ }^{2}$ Professor, Department of Mechanical Engineering, Jawaharlal Darda Institute of \\ Engineering \&Technology,Yavatmal, Maharashtra, India
}

\begin{abstract}
Inconel 718 contributes majorly out of overall nickel based alloy applications. Material characteristics like heat resistance, dimensional stability, expose to high temperature region prioritize its popularity. Since doe to age hardening property and high hardness it consider under the category of difficult to cut. In this work attempt has been made to develop model by using fuzzy based artificial intelligence for the turning operation to confirm predictability against actual response outcomes.
\end{abstract}

KEYWORDS: Difficult to cut, ANFIS, Inconel 718, Nickel Alloys

Received: May 17, 2017; Accepted: Jun 02, 2017; Published: Jun 13, 2017; Paper Id.: IJMPERDJUN201731

\section{INTRODUCTION}

The Inconel 718 is a nickel based alloy most famous in aerospace application. This material is most preferred in area expose to high temperature region. The high strength-weight ratios, resistant to corrosion, longer life period, mechanical as well as thermal fatigue, thermal shock, creep and erosion makes practical priority for its application. In this paper attempt has been made to develop predictive model by fuzzy based intelligence approach. The PVD coated carbide tool used for machining to get predictive responses. The cutting conditions analyze to minimizes cost of operation and maximize product surface quality.

\section{MACHINING ISSUES OF INCONEL 718}

The high hardness and ageing properties of the inconel 718 alloys results high temperature and stresses in the cutting zone causes flank wear, chattering and notching, has significant influence of cutting conditions of machining Ezugwu et al (1991).The machining faces high temperature stress, thick adhering layer at the tool-work interface. The chip braking is difficult since high toughness. These machining issues forms high tool wear lower material remove rate (MRR) and undesired surface quality. The induced stresses due to high cutting forces while machining, rises work hardening, surface tearing and distortion Rahman et al (1997). Choudhury et al (1998). The tendency to form a BUE in machining and the presence of hard carbide particles in microstructure deters machinability. The high speed and dry cutting is the big challenge to meet the economical machining prospective. 


\section{CONTRIBUTORS AND REVIEW IN TURNING WITH PVD COATED TOOL}

The use of PVD coatings for cutting tools in the cutting of hard alloy, have major contribution in the industrial application of modern machining operations. The use of PVD coated cutting tool is the most effective alternative for improving durability and surface's strength. Most of the contributor find appealing to work on marching of Inco alloy due to its wider application but having practical machining challenges. The choice of PVD coated tool is to extend machining quality and life. PC Jindal et al [1] used PVD TiN, TiCN, and high-ionization sputtered PVD inserts. Macrostructural and mechanical properties of the coatings and substrate were characterized and were evaluated in turning of Inconel 718. The characteristics are a result of the higher hot hardness and oxidation resistance of TiAlN at the temperatures normally encountered at the tool tip during machining operations. Y Kamata et al [2] applied TiN/AlN super lattice (PVD) and TiAlN (PVD) to finish-turning. The longest tool life was attained by TiCN/A12O3/TiN coating in wet cutting, but the surface finish was not good. A Bhatt et al [3] presents the results of an experimental investigation on the wear mechanisms of uncoated tungsten carbide (WC) and coated tools (single-layer (TiAlN) PVD, and triple-layer (TiCN/A12O3/TiN) CVD) in oblique finish turning of Inconel 718 it was concluded that abrasive and adhesive wear were the most dominant wear mechanisms, controlling the deterioration and final failure of the WC tools. D DudzinskI et al [4] attention is focussed on Inconel 718 and recent work and advances concerning machining of this material are presented. In addition, some solutions to reduce the use of coolants are explored, and different coating techniques to enable a move towards dry machining are examined Prengel et al [5] used different PVD coated carbide cutting tools at 61 and $76 \mathrm{~m} / \mathrm{min}$, The TiAlN-multilayer showed some advantages over the TiAlN-monolayer and TiN/TiCN/TiAlN-multilayer coating particularly at a higher speed of $76 \mathrm{~m} / \mathrm{min}$. The main failure mode in Inconel 718 machining was abrasive nose wear accompanied by plastic deformation The notching was heavily influenced by burr formation on the uncut diameter. Coated flaking was observed early in the cut at the depth of cut region for all the coated tools tested. C Ducros [6] taken adhesion tests by multilayer PVD tool and surface topography analyses indicate better adhesion and lower roughness for CrN/TiN than for TiN/AlTiN coatings. All these coatings, especially TiN/AlTiN nano layers, favorably influence flank wear and cutting time for machining Inconel 718 in relatively severe cutting conditions. M.Z.A. Yazid et al [7] investigated the effect of cutting parameters and machining conditions on surface integrity when finish turning Inconel 718 using PVD coated tool.

\section{EXPERIMENTATION}

The inconel 718 round bar of $\Phi 29 \mathrm{~mm}$ turned with PVD coated carbide SNMG 120408 cutting tool on Gildemeister CTX 310 Eco CNC Lathe in dry environment. The chemical composition and mechanical properties of the work piece are given in Tables 1 and 2, respectively.

Table 1: The Mechanical Properties of Inconel 718

\begin{tabular}{|c|c|}
\hline Density & $8.19 \mathrm{~g} / \mathrm{cm}^{\mathbf{3}}$ \\
\hline Melting point & $1260-1336{ }^{\mathbf{~} \mathrm{C}}$ \\
\hline Specific heat & $435 \mathrm{~J} / \mathrm{kg} \mathrm{K}$ \\
\hline $\begin{array}{c}\text { Average coefficient of thermal } \\
\text { expansion }\end{array}$ & $13 \mathrm{~lm} / \mathrm{m} \mathrm{K}$ \\
\hline Thermal conductivity & $11.4 \mathrm{w} / \mathrm{m} \mathrm{K}$ \\
\hline Ultimate tensile strength & $1240 \mathrm{MPa}$ \\
\hline
\end{tabular}


Table2: The Chemical Composition of Inconel 718

\begin{tabular}{|l|l|c|c|l|c|l|}
\hline Element & $\mathbf{N i}(+\mathbf{C o})$ & $\mathbf{T i}$ & $\mathbf{C r}$ & $\mathbf{N b}(+\mathbf{T a})$ & $\mathrm{Al}$ & $\mathbf{F e}+$ Other \\
\hline Weight (\%) & $50-55$ & $0.65-1.5$ & $17-21$ & $4.75-5.5$ & $0.2-0.8$ & Balance \\
\hline
\end{tabular}

The machining parameters speed of 30,50 and $60 \mathrm{~m} / \mathrm{min}$ considered at cutting feed $0.1,0.15$ and $0.2 \mathrm{~mm} / \mathrm{rev}$ with constant depth of cut of $0.2 \mathrm{~mm}$. Machining responses discussed as surface roughness and Material removal rate.

\section{DESIGN OF EXPERIMENT}

Three level two factorial DOE is prepared with constant depth of cut. Surface roughness and material removal rate are the machining responses. The various experimental observations as in table 3.

Table 3: Machining Observations for Turning of Inconel 718

\begin{tabular}{|c|c|c|c|c|c|c|c|}
\hline \multirow{2}{*}{ Runs } & \multirow{2}{*}{$\begin{array}{c}\text { Speed } \\
\mathbf{( m / m i n})\end{array}$} & $\begin{array}{c}\text { Feed } \\
(\mathbf{m m})\end{array}$ & $\begin{array}{c}\text { DoC } \\
(\mathbf{m m})\end{array}$ & $\mathbf{R a}($ Actual $)$ & Ra (Replicate) & MRR (Actual) & MRR (Replicate) \\
\cline { 5 - 8 } & 30 & 0.1 & 0.2 & 0.016 & 0.016 & 0.70527 & 0.77823 \\
\hline 2 & 30 & 0.15 & 0.2 & 0.016 & 0.015 & 1.07470 & 1.18783 \\
\hline 3 & 30 & 0.2 & 0.2 & 0.015 & 0.015 & 1.41055 & 1.61205 \\
\hline 4 & 50 & 0.1 & 0.2 & 0.014 & 0.014 & 1.18783 & 1.25382 \\
\hline 5 & 50 & 0.15 & 0.2 & 0.013 & 0.013 & 1.73606 & 1.88073 \\
\hline 6 & 50 & 0.2 & 0.2 & 0.012 & 0.012 & 2.50764 & 2.50764 \\
\hline 7 & 70 & 0.1 & 0.2 & 0.013 & 0.013 & 1.73606 & 1.73606 \\
\hline 8 & 70 & 0.15 & 0.2 & 0.013 & 0.012 & 2.82109 & 2.82109 \\
\hline 9 & 70 & 0.2 & 0.2 & 0.012 & 0.011 & 2.82109 & 3.22411 \\
\hline
\end{tabular}

\section{Regression Analysis: Ra and MRR Versus Speed, Feed}

Linear regression model prepare to find linear relationship between a Ra, MRR and predictor(s) (Speed, Feed). Normal probability correlated in figure 1 and figure 3 . The counter plots plotted out, to know the contribution of machining parameters on Ra and MRR. The regression equations are:

$\mathrm{Ra}=0.0233-0.000290$ Speed +0.0012 Feed +0.000002 Speed $^{2}-0.0333$ Feed $^{2}-0.000125$ Speed $^{*}$ Feed

MRR $=-1.59+0.0350$ Speed +11.1 Feed

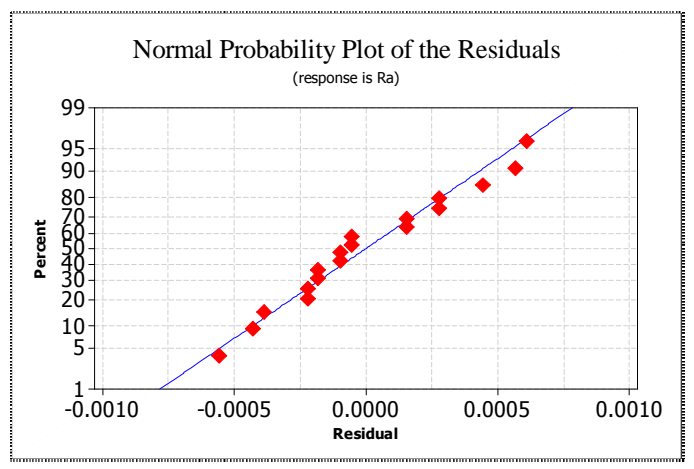

Figure 1: Residual Plot for Ra.

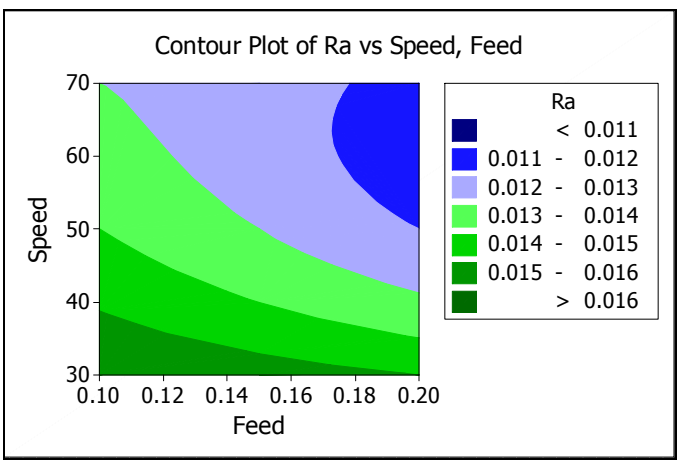

Figure 2: Counter Plot for Ra 


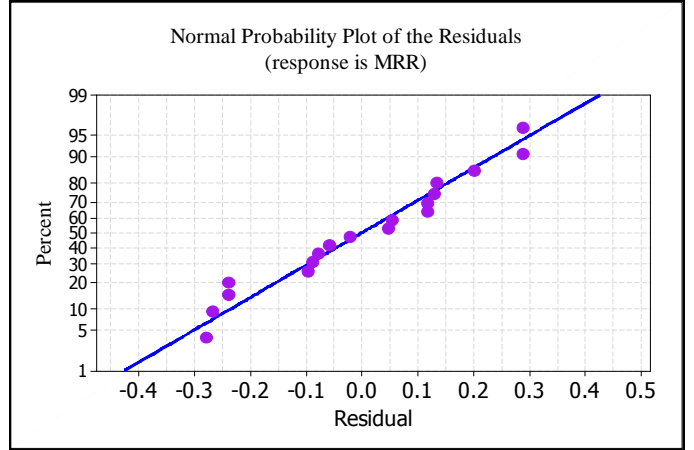

Figure 3: Residual Plot for MRR

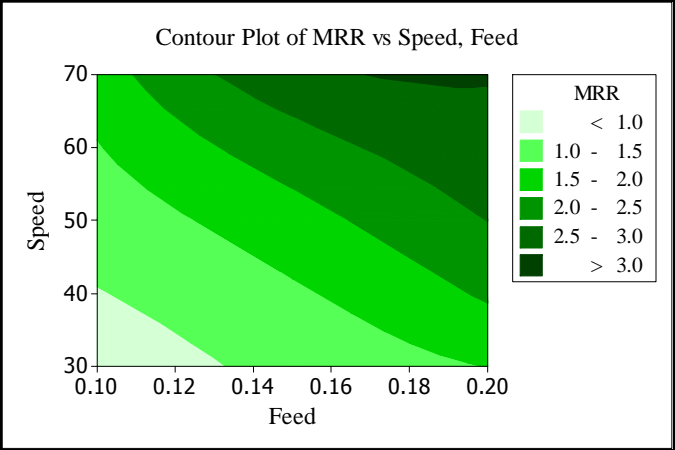

Figure 4: Counter Plot for MRR

\section{Fuzzy Intelligence Predictive Model}

Fuzzy logic is a efficient way to map input characteristics to output. In this work concept of fuzzy approach and development of predictive ANFIS model for surface roughness response at various speed and feed condition are discussed. The MATLAB 7.0 based Graphical User Interface (GUI) has been used to develop and test for its ability in modeling for Fuzzy logic is a efficient way to map input characteristics to output. In this work concept of fuzzy approach and machining by Adaptive Network-based Fuzzy Inference system (ANFIS). It has been validated to be capable of testing the best variable setting of the intended model in ANFIS environment ANFIS model developed with number 35 of nodes, 9 numbers of linear parameters, 18 numbers of nonlinear parameters, 27 total numbers of parameters, 18 numbers of training data pairs 9, and number of fuzzy rules.

Fuzzy inference is the process of formulating the mapping from a given input cutting speed, feed to an output Ra and MRR using fuzzy logic. The mapping then provides a basis from which decisions can be made, or patterns discerned Mamdani's fuzzy inference method is the most commonly seen fuzzy methodology. Mamdani's method was among the first control systems built using fuzzy set theory. A membership function (MF) is a curve that defines how each point in the input space is mapped to a membership value figure shows initial and final membership factions for Ra and MRR.
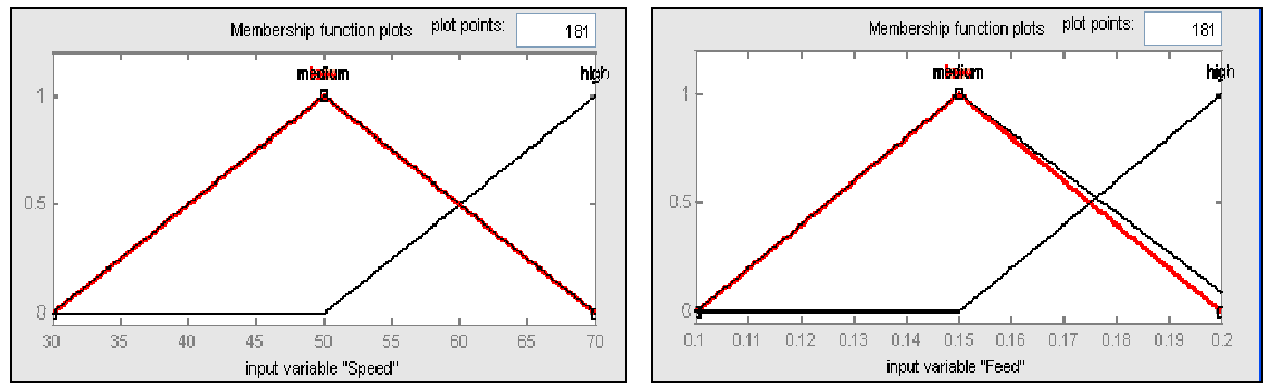

Figure 5: Initial Membership Function of Speed and Feed For Ra, MRR

The permutation combination for each individual responses ANFS forms fuzzy rules. In the rule viewer predicted response output surface roughness for random values of input variable speed and feed observed.

- If (Speed is Low) and (Feed is Low) then Ra/MRR is out $1 \mathrm{mf1}$

- If (Speed is Low) and (Feed is Medium) then Ra/MRR is out $1 \mathrm{mf} 2$

- If (Speed is Low) and (Feed is High) then Ra/MRR is out $1 \mathrm{mf} 3$ 
- If (Speed is Medium) and (Feed is Low) then Ra/MRR is out $1 \mathrm{mf} 4$

- If (Speed is Medium) and (Feed is Medium) then Ra/MRR is out $1 \mathrm{mf} 4$

- If (Speed is Medium) and ( Feed is High) then Ra/MRR is out $1 \mathrm{mf} 6$

- If (Speed is High) and (Feed is Low) then Ra/MRR is out $1 \mathrm{mf} 7$

- If (Speed is High) and ( Feed is Medium) then Ra/MRR is out $1 \mathrm{mf} 8$

- If (Speed is High) and ( Feed is High) then Ra/MRR is out $1 \mathrm{mf} 9$

Table 4: Response Table and Predicted Values of Ra and MRR (PVD)

\begin{tabular}{|c|c|c|c|c|c|c|c|c|c|}
\hline Runs & $\begin{array}{c}\text { Speed } \\
(\mathrm{m} / \mathrm{min})\end{array}$ & $\begin{array}{l}\text { Feed } \\
(\mathbf{m m})\end{array}$ & $\begin{array}{c}\text { DoC } \\
(\mathrm{mm})\end{array}$ & $\begin{array}{c}\text { Ra } \\
\text { (Actual) }\end{array}$ & $\begin{array}{c}\text { Ra } \\
\text { (Regression) }\end{array}$ & $\begin{array}{c}\text { Ra } \\
(\text { ANFIS) }\end{array}$ & $\begin{array}{c}\text { MRR } \\
\text { (Actual) }\end{array}$ & $\begin{array}{c}\text { MRR } \\
\text { (Regression) }\end{array}$ & $\begin{array}{c}\text { MRR } \\
\text { (ANFIS) }\end{array}$ \\
\hline & & & & $(\mu \mathrm{m})$ & $(\mu \mathrm{m})$ & $(\mu \mathrm{m})$ & $\left(\mathrm{cm}^{3} / \mathrm{min}\right)$ & $\left(\mathrm{cm}^{3} / \mathrm{min}\right)$ & $\left.\mathrm{cm}^{3} / \mathrm{min}\right)$ \\
\hline 1 & 30 & 0.10 & 0.2 & 0.0160 & 0.0158 & 0.0135 & 0.7053 & 0.5700 & 0.0750 \\
\hline 2 & 30 & 0.15 & 0.2 & 0.0160 & 0.0153 & 0.0135 & 1.0747 & 1.1250 & 1.0700 \\
\hline 3 & 30 & 0.20 & 0.2 & 0.0150 & 0.0146 & 0.0135 & 1.4106 & 1.6800 & 1.4100 \\
\hline 4 & 50 & 0.10 & 0.2 & 0.0140 & 0.0130 & 0.0135 & 1.1878 & 1.2700 & 1.1900 \\
\hline 5 & 50 & 0.15 & 0.2 & 0.0130 & 0.0123 & 0.0107 & 1.7361 & 1.8250 & 1.7400 \\
\hline 6 & 50 & 0.20 & 0.2 & 0.0120 & 0.0115 & 0.0135 & 2.5076 & 2.3800 & 2.5100 \\
\hline 7 & 70 & 0.10 & 0.2 & 0.0130 & 0.0117 & 0.0135 & 1.7361 & 1.9700 & 1.7400 \\
\hline 8 & 70 & 0.15 & 0.2 & 0.0130 & 0.0109 & 0.0124 & 2.8211 & 2.5250 & 2.8200 \\
\hline 9 & 70 & 0.20 & 0.2 & 0.0120 & 0.0100 & 0.0110 & 2.8211 & 3.0800 & 2.8200 \\
\hline
\end{tabular}

\section{RESULTS AND DISCUSSIONS}

The table shows the comparative assessment of actual outcomes with predictive model results of regression and ANFIS. The results of responses have good agreement with respect to trends. Figure 6 and Figure 7 show good agreement of predicted responses. The response values of machining of inconel 718 confirm the model adequacy with similar trend pattern

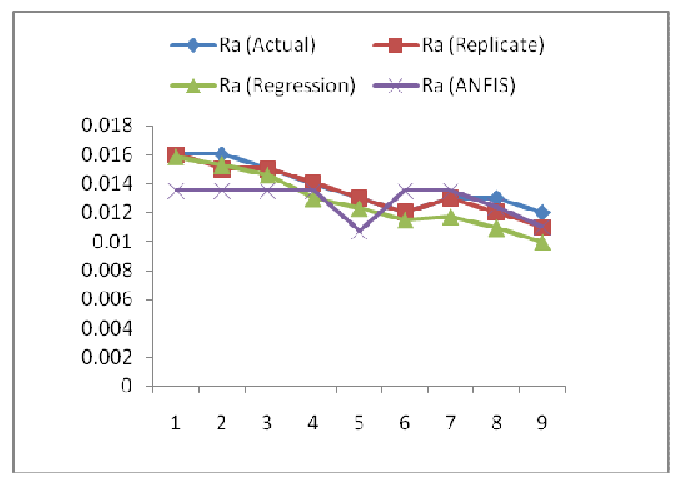

Figure 6: Comparative trend Ra

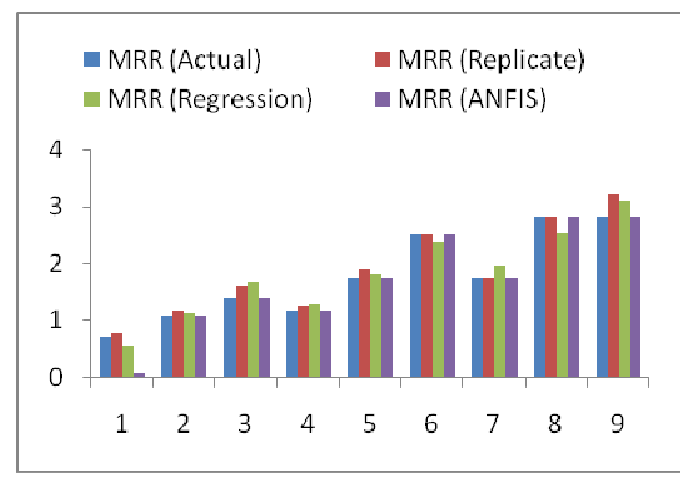

Figure 7: Colum chart of MRR 


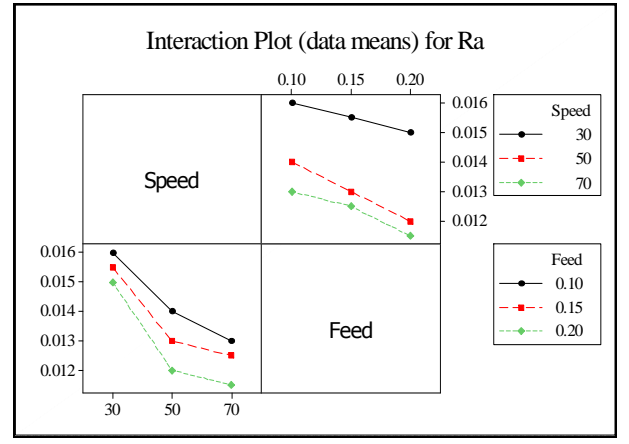

Figure 8: Interaction Plot for Ra.

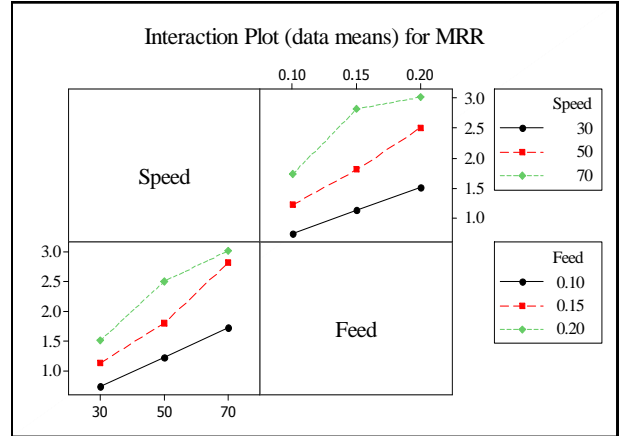

Figure 9: Interaction Plot for MRR

\section{CONCLUSIONS}

Artificial intelligence techniques now days focused on alternative for convenient and efficient technique in machining and manufacturing area. The economic trials burden can be overcome by fuzzy based inference productivity of marching response outcomes. The hard material inconel 718 difficult to machine, PVD coated carbide machining found to be suitable to estimate linear characteristics of machining.

\section{ACKNOWLEDGEMENTS}

Author thanks to COET Akola for availing facility of research laboratory and to Nashik Auto Cluster for experimentation support.

\section{REFERENCES}

1. Jindal PC, Santhanam AT, Schleinkofer U, Shuster AF. Performance of PVD TiN, TiCN, and TiAlN coated cemented carbide tools in turning. International Journal of Refractory Metals and Hard Materials. 1999 May 31; 17(1):163-70.

2. Kamata Y, Obikawa T. High speed MQL finish-turning of Inconel 718 with different coated tools. Journal of Materials Processing Technology. 2007 Oct 1; 192:281-6.

3. Bhatt A, Attia H, Vargas R, Thomson V. Wear mechanisms of WC coated and uncoated tools in finish turning of Inconel 718. Tribology International. 2010 Jun 30;43(5):1113-21.

4. Dudzinski D, Devillez A, Moufki A, Larrouquere D, Zerrouki V, Vigneau J. A review of developments towards dry and high speed machining of Inconel 718 alloy. International Journal of Machine Tools and Manufacture. 2004 Mar 31; 44(4):439-56.

5. Prengel HG, Jindal PC, Wendt KH, Santhanam AT, Hegde PL, Penich RM. A new class of high performance PVD coatings for carbide cutting tools. Surface and coatings technology. 2001 May 1;139(1):25-34.

6. Ducros C, Benevent V, Sanchette F. Deposition, characterization and machining performance of multilayer PVD coatings on cemented carbide cutting tools. Surface and coatings technology. 2003 Jan 30; 163:681-8.

7. Yazid MZ, CheHaron CH, Ghani JA, Ibrahim GA, Said AY. Surface integrity of Inconel 718 when finish turning with PVD coated carbide tool under MQL. Procedia Engineering. 2011 Jan 1; 19:396-401.

8. Rahman M., Seah W.,Teo T. "The machinability of Inconel 718”, Journal of Materials Processing Technology 63,(1997), pp.199-204.

9. T. Kitagawa, A. Kubo, K. Maekawa, "Temperature and wear of cutting tools in high speed machining of Inconel 718 and Ti6Al-6V-2Sn”, Wear 202 (1997) 142-148. 
10. Choudhoury IA, El-Baradie MA. "Machinability of nickel-base super alloys: a general review. Materials Processing Technology" (1998), 77:278-284.

11. P.C. Jindal, A.T. Santhanam, U. Schleinkofer, A.F. Shuster, "Performance of PVD TiN, TiCN and TiAlN coated cemented carbide tools in turning”, International Journal of Refractory Metals and Hard Materials 17 (1999) 163-170.

12. E.O. Ezugwu, Z.M. Wang, A.R. Machado, "The machinability of nickel-based alloys: a review", Journal of Materials Processing Technology 86 (1999), 1-16.

13. K. Itakura, M. Kuroda, H. Omokawa, H. Itani, K. Yamamoto, Y. Ariura, Wear mechanism of coated cemented carbide tool in coated tool in cutting of Inconel 718 super-heat resisting alloy, International Journal of Japanese Society for Precision Engineering 33 (4) (December 1999) 326-333.

14. C.A.Dandre, C.A.Walsh, R.W.Evans, R.C.Reed, and S.M.Roberts. "Microstructural evolution of nickel-base superalloy forgings during ingot-to-billet conversion: process modelling and validation”. In T.M.Pollock et al, editor, Superalloys (2000), TMS, USA, pages 85-94, 2000.

15. Mason, Wayne, “Inserts For Difficult Materials,” Modern Machine Shop, January 2002, pp. 82-86.

16. Ship-Peng Lo, "An adaptive-network based fuzzy inference system for prediction of work piece surface roughness in end milling”,Journal of Materials Processing Technology 142, pp. (2003) 665-675

17. Ezugwu E. O., "Key improvements in the machining of aero-engine alloys using self-propelled rotary tooling technique", Journal of Materials Processing Technology 185, (2007), pp. 60-71

18. R.Schafrik and R.Sprague. "The saga of gas turbine materials. Advanced Materials and Processes", 162:3:33-36, 4:27-30, 5:29-33, 6:41-46, 2004.

19. D. Dudzinski et at. (2004),Dudzinski A., Devillez A., Moufki A, Larrouque`re D, Zerrouki V., Vigneau J., “A review of developments towards dry and high speed machining of Inconel 718 alloy”, International Journal of Machine Tools \& Manufacture 44 (2004) 439-456

20. Ezugwu, E.O., Bonney,J., Fadare,D.A., Sales, W. F. “Machining nickel-base, Inconel 718, alloy with ceramic tools under conditions with various coolant supply pressures", Jour. of Mater. Proc. Tech., vol. 162-163, (2005), p. 68-73

21. Sharman ARC, Hughes JI, Ridgway K. “An analysis of the residual stresses generated in Inconel 718 when turning”. Journal of Materials Processing Technology (2006); 173:359-367.

22. Devillez, A., Schneider,F., Dominiak,S., Dudzinski, D., Larrouquere, D. "Cutting forces and wear in dry machining of Inconel 718 with coated carbide tools". Wear (2007) 262, 931-942.

23. Altin, M. Nalbant, A. Taskesen, "The effects of cutting speed on tool wear and tool life when machining Inconel 718 with ceramic tools", Materials and Design 28 (2007) 2518-2522

24. Thakur, D. G., Ramamoorthy B. Optimization of Minimum Quantity Lubrication Parameters in High Speed Turning of Inconel 718 for Sustainable Development”, World Academy of Science, Engineering and Technology 54 (2009) 224-226

25. Senthilkumaar JS, Selvarani P, Arunachalam RM. "Intelligent optimization and selection of machining parameters in finish turning and facing of Inconel 718”. The International Journal of Advanced Manufacturing Technology (2012); 58:885-894

26. Homami, R.M., Tehrani, A.F., Mirzadeh, H., Movahedi, B. and Azimifar, F. "Optimization of turning process using artificial intelligence technology”, International Journal of Advanced Manufacturing Technology. (2014) 70 (5-8) p. 1205-1217 
